\title{
Jeugd in Beeld geeft inzicht in de gezondheid van kinderen
}

\author{
P. van Dommelen · P. Zwijgers · O. Engelse · JIB-koplopersgroep
}

Published online: 26 January 2016

(C) Bohn Stafleu van Loghum 2016

Samenvatting Jeugd in Beeld (JIB) geeft alle Jeugdgezondheidszorg (JGZ)-organisaties de mogelijkheid om inzicht te krijgen in de gezondheid van hun populatie en dit te spiegelen aan andere JGZ-organisaties. Het doel van JIB is om beleids- en sturingsinformatie te leveren om de kwaliteit van de zorg te optimaliseren. Deelname aan JIB verloopt via het Nederlands Centrum Jeugdgezondheid (NCJ). De werkwijze van JIB is als volgt: (1) deelnemende JGZ-organisaties leveren anonieme gegevens, die geregistreerd zijn conform de Basisdataset, uit het Digitaal Dossier (DD) JGZ aan, (2) er vindt een kwaliteitscontrole van de data plaats, (3) de uitkomstmaten worden berekend en (4) via een beveiligde web-applicatie wordt er spiegelinformatie op wijk-, regionaal en landelijk niveau beschikbaar gesteld aan deelnemende JGZ-organisaties. Inmiddels zijn er zeven JGZ-organisaties die deelnemen aan JIB, waarvan zes gegevens hebben aangeleverd op het gebied van overgewicht bij 2- tot 4-jarigen. Dit artikel geeft inzicht in de werkwijze van JIB en presenteert resultaten op het gebied van overgewicht op basis van 41.441 kinderen op de contactmomenten 2 en 3 jaar en 3 jaar en 9 maanden over het jaar 2014.

Trefwoorden Overgewicht · Jeugdgezondheidszorg · digitaal dossier $\cdot$ basisdataset

Leden van de JIB-koplopersgroep staan in de appendix vermeld.

P. van Dommelen $(\bowtie) \cdot$ JIB-koplopersgroep

TNO,

Leiden, Nederland

Paula.vanDommelen@tno.nl

P. Zwijgers · O. Engelse $\cdot$ JIB-koplopersgroep

NCJ,

Utrecht, Nederland
Inleiding

Belanghebbenden bij de jeugdgezondheidszorg (JGZ) hebben behoefte aan gegevens voor het vormen en toetsen van beleid en het uitvoeren van onderzoek. Hierbij gaat het met name om spiegelgegevens voor JGZ-organisaties en gemeenten, beleidsinformatie voor gemeenten en rijksoverheid en gegevens voor epidemiologisch onderzoek bij GGD'en en andere onderzoeksinstellingen. Omdat dagelijks 6.000 artsen, verpleegkundigen en assistenten binnen de JGZ hun bevindingen over de groei en ontwikkeling van 0 - tot 18 -jarigen in het Digitaal Dossier (DD) JGZ rapporteren, is het mogelijk om deze gegevens hiervoor te gebruiken. Om hierin te voorzien is Jeugd in Beeld (JIB) ontstaan. JIB geeft alle JGZ-organisaties de mogelijkheid om anonieme kindgegevens conform de Basisdataset (BDS) uit het DD JGZ centraal te ontsluiten zodat er spiegelinformatie op wijk-, regionaal en landelijk niveau beschikbaar wordt gesteld. Deze informatie kan worden gebruikt voor benchmarking. Het doel van JIB is om beleids- en sturingsinformatie te leveren om de kwaliteit van de zorg te optimaliseren.

\section{Methode}

Een JGZ-organisatie kan via het Nederlands Centrum Jeugdgezondheid (NCJ) aansluiten bij JIB als zij de gevraagde gegevens (deels) registreren conform BDS. Op dit moment worden kindgegevens op het gebied van overgewicht, visus, psychosociale problemen, kindermishandeling, vrouwelijke genitale verminking en achtergrondkenmerken verzameld binnen JIB. Om aan te sluiten moet er een deelnameovereenkomst, reglement en bewerkersovereenkomst worden getekend, waarin de privacy, (gegevens)beveiliging en aansprakelijkheid is vastgelegd. Zeven JGZ-organisaties zijn op dit moment aangesloten bij JIB: Yunio (regio Oost-Gelderland), 
Thebe (regio West- en Midden-Brabant), Careyn (regio Breda), Thuiszorg West-Brabant, Zorggroep Oude en Nieuwe Land (Noordoostpolder, Urk en Steenwijkerland), GGD Limburg-Noord en GGD West-Brabant. Al deze JGZ-organisaties, behalve GGD West-Brabant, hebben gegevens aangeleverd op het gebied van overgewicht bij 2- tot 4-jarigen over het jaar 2014.

Vier stappen worden volgens de systematiek van JIB doorlopen om anonieme kindgegevens om te zetten naar resultaten op geaggregeerd niveau:

\section{Stap 1. Ontsluiten en aanleveren gegevens}

Twee keer per jaar worden de benodigde gegevens uit het DD JGZ ontsloten. De JGZ-organisatie splitst vervolgens de gegevens op in twee delen; het eerste deel bestaat uit achtergrondkenmerken op het gebied van geografie (viercijferige postcode/woonplaats/gemeente); het tweede deel met informatie specifiek over het onderwerp en overige achtergrondkenmerken (zoals geslacht/leeftijd/ lengte/gewicht). Beide bestanden worden via afzonderlijke kanalen (en beveiligd) aangeleverd. De koppeling van deze gegevens gebeurt met een JIB-ID nummer.

\section{Stap 2. Kwaliteitscontrole}

Gegevens (elementen) uit het DD JGZ kunnen mogelijk door technische of praktische problemen niet (volledig) worden aangeleverd. Om de volledigheid in kaart te brengen, controleren de JGZ-organisaties of:

1. Alle BDS-elementen (i.e. datavariabelen) aanwezig zijn in de bestanden (en zo niet, welke elementen ontbreken en wat de reden(en) hiervan is/zijn);

2. De range van antwoorden per element conform BDS is;

3. Het aantal kinderen in zorg per soort contactmoment volgens verwachting is;

4. Er BDS-elementen aanwezig zijn met $\geq 5 \%$ ontbrekende waarden (en wat de reden(en) hiervan is/zijn).

Vervolgens wordt de aangeleverde data binnen JIB gecontroleerd op:

1. Dubbele invoer. Er is sprake van dubbele invoer als er meerdere gegevens van een kind binnen een contactmoment zijn. Er kunnen wel gegevens van kinderen over meerdere contactmomenten in de data voorkomen.

2. Selectieve uitval van data. We controleren de volledigheid van de data binnen subgroepen (scholen/regio's/ type contactmoment).

3. Aannemelijkheid van de data. We controleren de onderliggende verdelingen, uitschieters en onmogelijke combinaties van antwoordcategorieën.

4. Correctie of herhaling van de procedure. In overleg met de JGZ-organisatie wordt besloten om onjuiste gegevens te verwijderen of te corrigeren, of om nieuwe data aan te leveren. In het laatste geval vindt herhaling van het hiervoor beschreven proces plaats.

\section{Stap 3. Berekening uitkomstmaten}

De uitkomstmaten worden per kind berekend. In het geval van overgewicht is de uitkomstmaat ondergewicht, normaal gewicht, overgewicht en obesitas. De berekeningen worden uitgevoerd volgens internationale of Nederlandse (JGZ-) richtlijnen en in overleg met experts op de specifieke onderwerpen binnen JIB.

\section{Stap 4. Presentatie van gegevens}

Het eindbestand wordt toegevoegd aan de web-applicatie Swing. Elke deelnemende organisatie kan de uitkomst bekijken op het niveau van de eigen organisatie, de wijken, postcodes of gemeente die onder de eigen organisatie vallen, of alle deelnemende JGZ-organisaties. Voor elk onderwerp wordt automatisch een standaardrapportage gegenereerd waarin de belangrijkste bevindingen worden getoond, maar de JGZ-organisatie kan ook zelf selecties op de data toepassen om rapportages naar eigen inzicht in te richten. In de rapportage worden uitkomsten alleen weergegeven als die op minimaal 37 kinderen zijn gebaseerd (i.e. drempelwaarde $\geq 37$ ). Met deze drempelwaarde is de breedte van het $95 \%$ betrouwbaarheidsinterval van een prevalentie maximaal $30 \%$.

Omdat JIB spiegelinformatie ter beschikking stelt, is er besloten om in dit artikel een JGZ-organisatie te selecteren, Yunio, waarvan de uitkomsten worden afgezet tegen alle deelnemende 0 tot 4 JGZ-organisaties.

\section{Statistische analyses 'Overgewicht'}

Met behulp van lengte en gewicht wordt de Body Mass Index (BMI: $\mathrm{kg} / \mathrm{m}^{2}$ ) uitgerekend en ingedeeld in de categorieën ondergewicht (thinness grades II + III samengenomen) [1], gezond gewicht, overgewicht en obesitas volgens de International Obesity Task Force (IOTF) afkapwaarden [2]. In dit artikel omvat de categorie overgewicht ook kinderen met obesitas. Uit onderzoek onder kinderen in Nederland blijkt dat overgewicht vaker voorkomt bij meisjes, kinderen van Turkse of Marokkaanse afkomst en laag opgeleiden [3, 4]. Daarom zijn ook gegevens over de etniciteit en de opleiding van de ouders of verzorgers gevraagd bij het onderwerp overgewicht. De indeling van etniciteit is gebaseerd op de CBS-definitie. Een kind is van Nederlandse afkomst als beide biologische ouders in Nederland zijn geboren. Een kind is van Turkse of Marokkaanse afkomst als ten minste een van de biologische ouders in respectievelijk Turkije of Marokko is geboren. Het opleidingsniveau van de ouder(s)/verzorger(s) is gedefinieerd als het opleidingsniveau van de ouder/ verzorger met de hoogste afgeronde opleiding voor zover gekend, ingedeeld in de categorieën laag (maximaal 
Tabel 1 Overzicht van het aantal kinderen waarover de gegevens op het gebied van overgewicht voor de contactmomenten 2 en 3 jaar en 3 jaar en 9 maanden over het jaar 2014 bekend zijn binnen JIB.

\begin{tabular}{|c|c|c|c|c|c|c|}
\hline \multirow[b]{2}{*}{ karakteristieken } & \multicolumn{3}{|l|}{ Yunio } & \multicolumn{3}{|c|}{ alle deelnemende 0 tot $4 \mathrm{JGZ}$-organisaties ${ }^{\mathrm{a}}$} \\
\hline & aantal totaal & aantal meisjes & aantal jongens & aantal totaal & aantal meisjes & aantal jongens \\
\hline totaal & 9.737 & 4.747 & 4.990 & 41.441 & 20.149 & 21.292 \\
\hline \multicolumn{7}{|l|}{ contactmoment } \\
\hline 2 jaar & 3.006 & 1.512 & 1.494 & 11.134 & 5.383 & 5.751 \\
\hline 3 jaar & 3.264 & 1.575 & 1.689 & 14.781 & 7.194 & 7.587 \\
\hline 3,9 jaar & 3.467 & 1660 & 1.807 & 15.526 & 7.572 & 7.954 \\
\hline \multicolumn{7}{|l|}{ afkomst } \\
\hline Nederlands & 7.388 & 3.548 & 3.840 & 32.257 & 15.680 & 16.577 \\
\hline Turks & 202 & 104 & 98 & 796 & 405 & 391 \\
\hline Marokkaans & 50 & 21 & 29 & 1.117 & 551 & 566 \\
\hline overig & 1.069 & 551 & 518 & 5.963 & 2.864 & 3.099 \\
\hline onbekend & 1.028 & 523 & 505 & 1.308 & 649 & 659 \\
\hline \multicolumn{7}{|l|}{ opleiding } \\
\hline laag & 400 & 206 & 194 & 2.608 & 1.268 & 1.340 \\
\hline midden & 2.835 & 1.384 & 1.451 & 11.423 & 5.514 & 5.909 \\
\hline hoog & 3.044 & 1.472 & 1.572 & 13.488 & 6.596 & 6.892 \\
\hline onbekend & 3.458 & 1.685 & 1.773 & 13.922 & 6.771 & 7.151 \\
\hline
\end{tabular}

mavo/vmbo-gl\&tl), middelhoog (mbo, havo/vwo) en hoog (hbo/hts/heao, wo) [5].

Lengte, gewicht, BMI en lengte-naar-gewicht-metingen die meer dan vijf standaarddeviaties afwijken ten opzichte van de mediaan van het groeidiagram van de algemene populatie [6], worden als onjuist beschouwd. Voor het onderwerp overgewicht worden kinderen die 2 jaar of ouder zijn geselecteerd, omdat er alleen afkappunten voor overgewicht vanaf 2 jaar beschikbaar zijn.

Binnen Swing wordt een standaardrapportage overgewicht gegenereerd. In dit artikel wordt een selectie van deze rapportage weergegeven. Een volledige voorbeeldrapportage is te vinden via de website https://www.ncj. $\mathrm{nl} /$ informatisering/jeugd-in-beeld

\section{Resultaten}

\section{Opschoning en selectie van data}

De zes betrokken JGZ-organisaties leverden gegevens aan over lengte en gewicht van in totaal 75.073 kinderen in de leeftijd van 1 tot 11 jaar over het jaar 2014. In totaal waren 7.105 (9\%) gegevens dubbel/duplicaat binnen een contactmoment. Bij 831 (1\%) kinderen week de leeftijd af van het soort contactmoment, bij $251(<1 \%)$ kinderen ontbraken de gegevens over lengte, gewicht of geslacht en bij $42(<1 \%)$ kinderen week de lengte, het gewicht, de BMI of de gewicht-naar-lengte meer dan vijf standaarddeviaties af ten opzichte van de mediaan. Na exclusie van dubbele en onjuiste gegevens bleven er 66.844 kinderen $(89 \%)$ over, waarvan 43.658 op de contactmomenten 2 jaar en 3 jaar, of 3 jaar en 9 maanden en 41.441 ouder of gelijk aan 2 jaar. Tabel 1 toont een overzicht van het aantal kinderen binnen Yunio en alle deelnemende 0 tot 4 JGZ-organisaties, uitgesplitst naar contactmoment, afkomst en opleiding.

\section{Overgewicht}

Tabel 2 geeft het percentage overgewicht voor meisjes, jongens en het totaal uitgesplitst naar contactmoment, afkomst en opleiding voor Yunio ten opzichte van alle deelnemende JGZ-organisaties weer. Het merendeel van deze informatie wordt in de JIB-rapportage ook grafisch voorgesteld. Uit tabel 1 blijkt dat het percentage overgewicht en obesitas binnen Yunio nagenoeg gelijk is aan deze percentages bij alle deelnemende JGZ-organisaties. Voor alle deelnemende JGZ-organisaties samen geldt dat het percentage overgewicht geleidelijk toeneemt met de leeftijd. Binnen Yunio zien we alleen een stijging in het percentage overgewicht tussen het contactmoment van 2 en 3 jaar. We zien grote verschillen in het percentage overgewicht tussen kinderen van Nederlandse, Turkse en Marokkaanse afkomst. Overgewicht komt 2,1 keer vaker voor bij meisjes van Marokkaanse afkomst en 2,4 keer vaker voor bij meisjes van Turkse afkomst ten opzichte van meisjes van Nederlandse afkomst. Ook geldt dat overgewicht 2,4 keer vaker voorkomt bij Marokkaanse jongens en Turkse jongens ten opzichte van jongens van Nederlandse afkomst. Eenzelfde patroon zien we binnen Yunio voor de Turkse en Nederlandse kinderen. Yunio heeft onvoldoende data (onder de drempelwaarde) van kinderen van Marokkaanse afkomst zodat hier geen uitspraak over kan worden gedaan. Verder laten de gegevens 
Tabel 2 Overzicht van het percentage kinderen met overgewicht waarover de gegevens voor de contactmomenten 2 en 3 jaar en 3 jaar en 9 maanden over het jaar 2014 bekend zijn binnen JIB.

\begin{tabular}{|c|c|c|c|c|c|c|}
\hline \multicolumn{4}{|c|}{ Yunio } & \multicolumn{3}{|c|}{ alle deelnemende 0 tot $4 \mathrm{JGZ}$-organisaties ${ }^{\mathrm{a}}$} \\
\hline karakteristieken & $\%$ overgewicht totaal & $\begin{array}{l}\% \text { overge- } \\
\text { wicht meisjes }\end{array}$ & $\%$ overgewicht jongens & $\%$ overgewicht totaal & $\%$ overgewicht meisjes & $\%$ overgewicht jongens \\
\hline totaal & 8,5 & 10,0 & 7,1 & 8,1 & 9,5 & 6,9 \\
\hline \multicolumn{7}{|l|}{ contactmoment } \\
\hline 2 jaar & 7,3 & 8,6 & 5,9 & 7,6 & 8,7 & 6,5 \\
\hline 3 jaar & 9,2 & 10,3 & 8,2 & 7,9 & 9,2 & 6,8 \\
\hline 3,9 jaar & 9,0 & 11,0 & 7,1 & 8,7 & 10,2 & 7,3 \\
\hline \multicolumn{7}{|l|}{ afkomst $^{\mathrm{b}}$} \\
\hline Nederlands & 8,0 & 9,2 & 6,9 & 7,2 & 8,4 & 6,1 \\
\hline Turks & 16,8 & 18,3 & 15,3 & 17,7 & 20,5 & 14,8 \\
\hline Marokkaans & & & & 16,0 & 17,4 & 14,7 \\
\hline \multicolumn{7}{|l|}{ opleiding } \\
\hline laag & 13,8 & 17,0 & 10,3 & 12,7 & 14,1 & 11,3 \\
\hline midden & 9,9 & 11,0 & 9,0 & 9,0 & 9,9 & 8,1 \\
\hline hoog & 6,3 & 7,1 & 5,6 & 6,9 & 8,2 & 5,7 \\
\hline
\end{tabular}

duidelijke verschillen zien in het percentage overgewicht tussen zowel meisjes als jongens van laag, middelhoog en hoog opgeleide ouders/verzorgers. Overgewicht komt 1,8 keer vaker voor bij laag opgeleide ouders/verzorgers en 1,3 keer vaker bij meisjes met middelhoog opgeleide ouders/verzorgers ten opzichte van meisjes van hoog opgeleide ouders/verzorgers. Binnen Yunio is het verschil in overgewicht tussen laag en hoog opgeleide ouders/verzorgers bij meisjes groter dan bij alle JGZorganisaties en bij jongens is het verschil vergelijkbaar.

Figuur 1 laat sterke verschillen in het percentage overgewicht zien voor de verschillende postcodegebieden binnen het zorggebied van Yunio. Voor de witte gebieden is onvoldoende data (onder de drempelwaarde) van kinderen beschikbaar.
Figuur 1 Percentage overgewicht (inclusief obesitas) in categorieën van laag $(0-5 \%)$ naar hoog $(>20 \%)$ voor de verschillende postcodegebieden binnen de JGZ-organisatie Yunio.

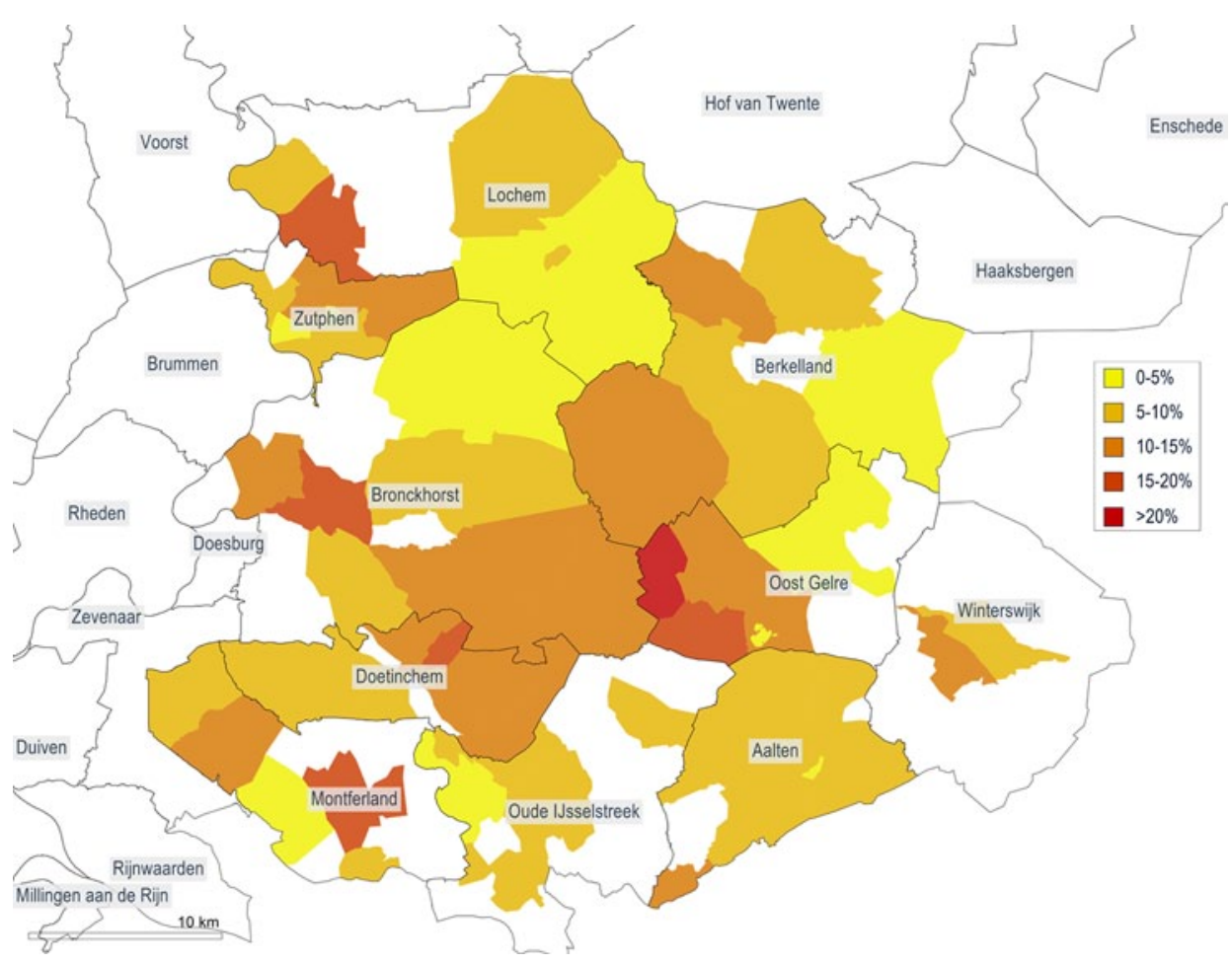




\section{Discussie}

JIB geeft alle JGZ-organisaties de mogelijkheid om inzicht te krijgen in de gezondheid van hun populatie op verschillende niveaus (wijk/gemeente), dit te spiegelen aan andere JGZ-organisaties en deze informatie op verzoek te delen met hun netwerk (overheid, scholen, jeugdhulp, etc.). Aansluiting is mogelijk door gegevens uit het DD JGZ conform BDS aan te leveren. De JIB-data uit 2014 laten zien dat er binnen de regio's Oost-Gelderland, West-Brabant, Limburg-Noord en Noordoostpolder, Urk en Steenwijkerland bij een op elf meisjes en een op veertien jongens in de leeftijd van 2 tot 4 jaar sprake is van overgewicht. Overgewicht komt twee keer zo vaak voor bij kinderen van Marokkaanse en Turkse afkomst ten opzichte van kinderen van Nederlandse afkomst en ook vaker bij kinderen met laag opgeleide ouders/verzorgers.

Ten opzichte van de landelijke gegevens uit 2009 [3], ligt het percentage van 2- tot 4-jarigen met overgewicht binnen de zes regio's lager bij zowel meisjes ( $9,5 \%$ vs. $12,5 \%$ landelijk) als jongens (6,9\% vs. 8,3\% landelijk). $\mathrm{Na}$ selectie van kinderen van Nederlandse afkomst zijn deze verschillen nog groter. Een deel van deze verschillen is mogelijk te verklaren door de afwezigheid van grote steden, waar de prevalentie van overgewicht hoger is $[3,7]$. Mogelijk speelt het periodeverschil een rol van betekenis. Een studie in Den Haag laat zien dat de prevalentie van overgewicht bij 3- tot 16-jarigen van Nederlandse afkomst licht is gedaald tussen 1999 en 2011, namelijk van $13 \%$ naar $11 \%$ [7]. De komende jaren kan JIB verder inzicht bieden in de trendcijfers.

Beperkingen van JIB zijn dat we aannemen dat de aangeleverde gegevens van voldoende kwaliteit zijn en conform BDS worden aangeleverd. Ondanks de toetsing volgens het kwaliteitsprotocol, kan het voorkomen dat in de beginfase van JIB de gegevens onvolledig zijn of onvolkomenheden bevatten. Vooral de gevoelige onderwerpen, zoals kindermishandeling en vrouwelijke genitale verminking werden niet conform de BDS geregistreerd of waren minimaal gerapporteerd. Daarmee zijn deze gegevens (vooralsnog) niet bruikbaar om in beeld te brengen.

Daarnaast is de volledigheid van de data van belang. We vragen specifiek aan de deelnemende JGZ-organisatie om dit binnen hun eigen data na te gaan, omdat bij het ontbreken van volledige records we hier geen zicht op hebben. Organisaties verrichten hierbij inspanningen om de eigen registratie te controleren. Registratieprotocollen en afspraken en de implementatie, borging en onderhoud hiervan zijn hierbij van belang. Binnen JIB worden de data nader bekeken of een selectie van gegevens ontbreekt. Ook bleek uit de analyses dat er vaak sprake was van dubbele registraties. Een reden hiervoor kan zijn dat achtergrondkenmerken, zoals etniciteit van de moeder en vader, elk apart worden gekoppeld aan de overige elementen, waardoor gegevens dubbel in het bestand terecht komen. Verder is het nodig dat meer JGZ-organisaties aansluiten zodat de resultaten binnen JIB een landelijk representatief beeld gaat vormen. Ook kunnen er verschillen in de wijze van registreren en in de mate van gebruik van richtlijnen ontstaan op het niveau van de organisatie en op het niveau van de JGZ-professional. Gedurende dit project kwam bij de deelnemende JGZ-organisaties de kwaliteit van de registratie hoog op de agenda te staan en gingen beleidsmakers onderling met elkaar in gesprek om een mogelijke verbeterslag te maken. Sterke punten van JIB zijn het geven van een impuls voor de (zorg)kwaliteitsverbetering (IGZ), de uniformering (impuls voor registratieverbetering), de co-creatie en samenwerking, de laagdrempelige toegang tot (statistische) kennis, vergelijkbare data door toepassing van dezelfde methodologie en de uniforme en actuele gegevens aan gemeenten. Dit laatste past goed bij de nieuwe taak die de JGZ met ingang van 1 januari 2015 heeft, namelijk die van beleidsadvisering naar gemeenten.

Er bestaan meerdere projecten die de gezondheid van kinderen in kaart brengen. Projecten die, in tegenstelling tot JIB, vooral gebruik maken van zelf gerapporteerde data zijn onder andere Gezond opgroeien. Verkenning jeugdgezondheid [8], de Landelijke Jeugdmonitor [9] en de Volksgezondheid Toekomst Verkenning [10], die elke vier jaar wordt uitgebracht. Ook het Health Behaviour in School-aged Children onderzoek wordt elke vier jaar uitgevoerd in meer dan 40 landen onder auspiciën van de Wereldgezondheidsorganisatie [11]. Daarnaast bestaat de Strategische Benchmark GGD. Deze heeft als doel om te spiegelen en te leren, maar niet om te verantwoorden. De strategische benchmark is er alleen voor GGD'en, terwijl JIB voor alle JGZ-organisaties bedoeld is. Gezamenlijk kunnen deze projecten bijdragen aan het inzichtelijk maken van de gezondheid van alle kinderen in Nederland.

JIB kan een belangrijke bijdrage leveren aan beleidsen sturingsinformatie om de kwaliteit van de JGZ te optimaliseren; niet alleen lokaal, maar ook regionaal en landelijk. JIB-rapportages zijn gebaseerd op uniforme, door professionals, geregistreerde data. De waarde van JIB wordt groter naarmate er meer conform de BDS wordt geregistreerd en naar gelang meer organisaties aansluiten.

Meer informatie is beschikbaar op de NCJ website www.ncj.nl/informatisering/jeugd-in-beeld.

\section{Financiering}

JIB is in opdracht van en gefinancierd door het Ministerie van VWS.

\section{Appendix}

De leden van de JIB-koplopersgroep bestaan uit de volgende personen:

Daphne de Lange (Thebe), Erica Stam (Yunio), Marlien Schep (Yunio),

Martijn Kuipers (GGD West-Brabant), Ria van Berlo (Limburg-Noord) en Rian Jonker

(Zorggroep Oude en Nieuwe Land). 


\section{Literatuur}

1. Cole TJ, Flegal KM, Nicholls D, Jackson AA. Body mass index cut offs to define thinness in children and adolescents: international survey. BMJ. 2007;335(7612):194.

2. Cole TJ, Bellizzi MC, Flegal KM, Dietz WH. Establishing a standard definition for child overweight and obesity worldwide: international survey. BMJ. 2000;320(7244):1240-3.

3. Schönbeck Y, Talma H, Dommelen P van, Bakker B, Buitendijk SE, Hirasing RA, Buuren $S$ van. Increase in prevalence of overweight in Dutch children and adolescents: a comparison of nationwide growth studies in 1980, 1997 and 2009. PLoS One. 2011;6(11):e27608.

4. Dommelen P van, Schönbeck Y, Buuren S van, HiraSing RA. Trends in a life threatening condition: morbid obesity in dutch, Turkish and Moroccan children in The Netherlands. PLoS One. 2014;9(4):e94299.

5. Verweij A, RIVM. Onderwijsdeelname: Indeling opleidingsniveau. Volksgezondheid Toekomst Verkenning, Nationaal Kompas Volksgezondheid. Bilthoven: RIVM, http:// www.nationaalkompas.nl

6. Schönbeck Y, Talma H, Dommelen P van, Bakker B, Buitendijk SE, HiraSing RA, Buuren S van. The world's tallest nation has stopped growing taller: the height of Dutch children from 1955 to 2009. Pediatr Res. 2013;73(3):371-7.
7. Wilde JA de, Verkerk PH, Middelkoop BJ. Declining and stabilising trends in prevalence of overweight and obesity in Dutch, Turkish, Moroccan and South Asian children 3-16 years of age between 1999 and 2011 in the Netherlands. Arch Dis Child. 2014;99(1):46-51.

8. Hamberg- van Reenen HH, Meijer SA, Gils PF van, Savelkoul M. Gezond opgroeien: verkenning jeugdgezondheid. Bilthoven: Rijksinstituut voor Volksgezondheid en Milieu (RIVM), 2014.

9. Jaarrapport: landelijke jeugdmonitor. Den Haag/ Heerlen: Centraal Bureau voor de Statistiek (CBS); 2014.

10. Schoemaker C, Loon J van, Hoeymans N. Een trendscenario en vier perspectieven voor 2040. Ned Tijdschr Geneeskd. 2014;158:A7477.

11. De Looze M, Dorsselaer S van, Roos S de, Verdurmen J de, Stevens G, Bon-Martens MJH van, Bogt T ter, Vollebergh W. HBSC 2013: gezondheid, welzijn en opvoeding van jongeren in Nederland. Utrecht: Universiteit Utrecht; 2014.

P. van Dommelen, statisticus/onderzoeker.

P. Zwijgers, senior adviseur.

o. Engelse, adviseur/projectleider Jeugd in Beeld. 